Richmond survey of 1869 , as part of the enlargement officially completed in 1862 . It has already been mentioned that quantities of coal in the canal fill of the second phase of construction on this prism were thought to indicate that this dredging and widening operation took place after the advent of steam engine traffic on the canal. The steam vessel, the A. M. Dawson first sailed the canal in 1871 and by 1874 there were fiftcen steamers on the canal (Whitford 1906:967). The second phase of construction on the enlargement canal probably took place as part of the final canal enlargement in 1895.

These conclusions reached as a result of minimal historic and archaeological research lack the conclusiveness which would be generated by an intensive search of historic clocu- mentation and further excavations. New York's canal system poses many fascinating problems for scholars interested in the history of commerce and transportation. The application of historic archaeology to these problems has added new data but it has also raised new questions which we hope will stimulate additional research. It seems quite clear that this research will require the close cooperation of historians and archaeologists.

\section{References Cited}

Maxon, E. T., M. Earl Carr and E. H. Stevens

1915 Soil Survey of Oneida County, New York. U. S. Department of Agriculture, Washington, D. C.

WhitFord, Noble E.

1906 The Canal System of The State of New York. Albany.

\title{
POST-1800 HISTORICAL INDIAN SITES
}

\section{by Roderick Sprague.}

\section{ABSTRACT}

The identification and interpretation of artifactual material in Indian sites is especially difficult, because we are making an analysis in terms of our own cultural background. A Euroamerican site presents a challenge to our observations only in terms of a time differential, but the Indian site has differences both in time and cultural heritage. In Linton's terms you have the same form but the function and meaning may be entirely different.

In studies of acculturation, especially material culture, the Indian site offers a special chance to study the impact of a donor culture on the receiving culture. Examples of theoretical constructs that could be tested in historical Indian sites would be Barnett's ideas concerning innovation, Foster's concepts of cultural crystalization, and an example already mentioned elsewhere by Lyle Stone, Spicer's ideas on the roles of individuals in culture change. Routes and rates of diffusion also can be studied through a large series of Indian sites.

Indian sites are well suited to studies of technological change. As an example from my own experience in an Indian site we found a complete change from wooden digging sticks to iron digging sticks in a very brief time span. In this example the mate- rial changed, but the shape remained unchanged along with the function and probably the meaning.

Changes in settlement patterns also are well suited to study through historical Indian sites. Other problems worthy of study are: how has a change in the basic economy changed settlement patterns and how much has the clonor culture affected the aboriginal pattern. The comments by Edwin Dethlefsen elsewhere concerning demographic data from cemeteries can certainly be applied to Indian cemeteries with certain limits. Markers will be less frequent, but data are still available concerning age, sex, and infant mortality.

A final suggestion for problem oriented research in historical Indian sites is in the area of informant work. The archaeologist working with the ethnologist could locate an abandoned village site that still has living former residents. The archaeologist would dig the site, while the ethnologist would work with the informants, thus the two researchers would feed data back and forth to each other to their mutual benefit. This technique would not only provide useful data to the historical archaeologist and ethnologist, but might also give new insight into the interpretations of local prehistoric archaeology. 